\title{
Enhanced Cancer Subtyping via Pan- Transcriptomics Data Fusion, Monte-Carlo Consensus Clustering, and Auto Classifier Creation
}

\author{
Kristofer Linton-Reid ${ }^{\dagger}$ \\ Imperial College London \\ South Kensington, London, United \\ Kingdom \\ k.linton-reid18@imperial.ac.uk
}

\author{
Harry Clifford \\ Cambridge Cancer Genomics \\ Cambridge, United Kingdom \\ harry@cancergenomics.co.uk
}

\author{
Joe Sneath Thompson \\ Cambridge Cancer Genomics \\ Cambridge, United Kingdom \\ joethompson@cancergenomics.co.
}

uk

\begin{abstract}
Subtyping of tumor transcriptome expression profiles is a routine method used to distinguish tumor heterogeneity. Unsupervised clustering techniques are often combined with survival analysis to decipher the relationship between genes and the survival times of patients. However, the reproducibility of these subtyping based studies is poor. There are multiple reports which have conflicting subtype and gene-survival time relationship results. In this study, we introduce the issues underlying the lack of reproducibility in transcriptomic subtyping studies. This problem arises from the routine analysis of small cohorts $(<100$ individuals) and use of biased traditional consensus clustering techniques. Our approach carefully combines multiple RNA-sequencing and microarray datasets, followed by subtyping via Monte-Carlo Consensus Clustering and creation of deep subtyping classifiers. This paper demonstrates an improved subtyping methodology by investigating pancreatic ductal adenocarcinoma. Importantly, our methodology identifies six biologically novel pancreatic ductal adenocarcinoma subtypes. Our approach also enables a degree of reproducibility, via our pancreatic ductal adenocarcinoma classifier PDACNet, which classical subtyping studies have failed to establish.
\end{abstract}

\section{KEYWORDS}

Consensus Clustering, Cancer Subtyping, Gene Expression, Pancreatic Cancer, RNA-Sequencing data, MicroArray data

\section{INTRODUCTION}

Subtyping of tumoral transcriptomic expression data is a key method in cancer informatics. These studies involve division of heterogeneous tumour populations into clinically and biologically distinct subtypes. Tumour tissues, from the same location, that appear morphological similar may have significantly different molecular features. This may attribute to variable responses to therapy and clinical outcomes. Once molecular subtypes of a cancer are defined, they can guide the use of therapies and treatment options, within trials and clinically.

Tumoral subtypes are usually distinguished by employing unsupervised consensus clustering techniques on expression datasets. After clustering, these subtypes are typically biologically validated via Kaplan-Meier survival analysis. This infers how expression changes and analogous subtypes affect the treatments and progression of cancer.

There are several gene expression based subtyping studies that cover a range of cancer types. However, a bottleneck here is the inconsistency between studies. Different cohorts and clustering techniques can produce very different subtyping results. Reports on the clustering of epithelial ovarian cancer have distinguished 4 to 6 subtypes [2,12,29,32]. Similarly, colorectal cancer has been classified into 3 to 6 subtypes [10]. Pancreatic cancer has been considered to comprise of 2 to 6 subtypes [[1,3,5,21,34,38]].

With the multiple inconsistencies in consideration, the current framework of subtyping needs developing further. There are two main weaknesses in the majority of subtyping studies. These stem from the use of small cohorts ( $<100$ samples) and the use of unsupervised consensus clustering techniques, usually nonnegative matrix factorisation (NMF), to distinguish subtypes.

The issue with using small cohorts is that each subtype may only be made up of a few stable samples, meaning only a few samples 
'fit' into the cluster. Sample stability is indicated by silhouette widths, these values are a measurement of how similar a sample is to its own cluster compared to other clusters. It is clear clusters made up of only a few samples with a silhouette width $>0.5$ (out of 1) would not represent a population accurately. It is unlikely that analysing expression data of small cohorts will accurately distinguish rarer subtypes. Dieci et al's study on breast cancer [4] demonstrated that rare subtypes of breast cancer exist with distinct molecular profiles and responses to treatment. It is clear that more comprehensive subtyping studies must be conducted in order to improve precision medicine treatment decisions.

The main problem with traditional consensus clustering techniques is that they are prone to discovering false positives. In other words, they may indicate the incorrect number of clusters (K). The false positive issue rises from three main weaknesses. The first two weaknesses arise from issues of the clustering techniques. Traditional consensus clustering has an inability to reject the null hypothesis that $\mathrm{K}=1$; and is subject to the inherent stability bias, defined as the tendency of cluster stability to increase as the number of clusters increases (and as the number of samples per cluster is reduced). The third issue originates from the RNA sequencing data itself. This sequencing data has a negative binomial distribution. Pacheco et al. [22] distinguished that negatively binomial distributed data can be classified into varying clusters of various sample sizes, and this dramatically alters performance on clusterlevel t-tests. The traditional clustering techniques will fail to account for the over-dispersion of RNA-seq expression data. For example, the popular NMF clustering technique has been reported to produce mixed results that deviate depending upon the starting point [8].

Stemming from the traditional subtyping study design issues, there are reports on inconsistencies existing between studies. There is a challenge in reproducing clusters from the same datasets using different techniques. John et al., [40] displayed reproducibility issues in 5 cancer NMF based subtyping studies, using their novel clustering technique Monte Carlo Consensus Clustering (M3C).

Despite these clear reproducibility issues, there have been no attempts to directly address them. There are three key improvements that can be implemented to remove the bottleneck of the current gene expression subtyping pipeline. The first is to increase the number of patients involved in each study, which should include incorporating multiple international cohorts and increasing the number of samples per cluster. The second is to perform a more robust subtyping method, which rejects the null hypothesis that $\mathrm{K}=1$, and accounts for the inherent stability bias. The third is to build classifiers based upon the subtyping annotations, which to an extent would allow subtyping of 'new' samples being added to a cohort post clustering.
In this study we employed our enhanced subtyping methodology on a pancreatic cancer dataset. Specifically, we focused on the pancreatic ductal adenocarcinomas (PDAC) subtype expression profiles, derived from tumor biopsies.

We created the largest open source transcriptomic pancreatic ductal adenocarcinoma dataset to date (1013 patients) by combining open source microarray and RNA-Seq datasets (Table 1). This addresses one of the main challenges when subtyping small cohorts, sample bias. This is a clear problem with PDAC cohorts as $80 \%$ of individuals are diagnosed at late stages [17]. Small cohorts typically capture late stage PDAC, and as previously mentioned cannot form accurate and stable clusters.

To distinguish subtypes, we employed John et al's novel M3C algorithm [40]. This technique is an improvement from traditional clustering techniques as it both allows rejection of the null hypothesis that there is only one subtype and removes the inherent stability bias.

As well as removing the small cohort issue and clustering problems, we performed the standard subtype clinical and biological validation. This was addressed via a Kaplan-Meier survival analysis and differential expression (DE) analysis.

The last step was our novel use of subtype annotations to build a deep learning classifier PDACNet. The creation of tumoral subtype classifiers is ideal for reproducing subtyping results on other tumoral cohorts.

\section{METHODS}

We developed the largest open source transcriptomic pancreatic ductal adenocarcinoma dataset (section 2.1) and created a novel pipeline for gene expression subtyping (section 2.2).

\subsection{PDAC Dataset Creation}

To create this large data set of PDAC expression values, we gathered data from a variety of repositories. These repositories included the International Cancer Genome Consortium (ICGC, www.icgc.org), the Cancer Genome Atlas (TCGA, http://cancergenome.nih.gov/), and Pubmed's Gene Expression Omnibus (GEO, http://www.ncbi.nlm.nih.gov/geo/). This dataset was created by combining 11 publicly available PDAC Microarray datasets, and 3 RNA-sequencing datasets derived from solid tumor biopsies (Table 1). The 11 publicly available Microarray datasets were merged by matching gene IDs and then batch corrected via ComBat [15], resulting in a dataset of 710 PDAC samples. The same technique was used for the 3 RNA-Sequencing datasets, forming a dataset of 303 samples. The RNA- Sequencing dataset 
was then normalized to the Microarray dataset, using feature specific quantile normalization [6,7]. Principal Component Analysis (PCA) score plots and Scree Plots, for Microarray and RNA data set integration are in Appendix Figures 1 and 2.

\section{Table 1 Sources of data. All data used in this study}

\subsection{Subtyping Pipeline}

The subtyping approach encompasses 4 key components. 1) Clustering with M3C, 2) Biological validation via Kaplan-Meier survival analysis, 3) Differential Expression and Gene Set

\begin{tabular}{|l|l|l|}
\hline Reference & $\begin{array}{l}\text { Number of } \\
\text { Samples }\end{array}$ & Source \\
\hline \multicolumn{2}{|c|}{ Microarray } \\
\hline Collinson et al., [3] & 27 & Collinson \\
\hline Ishikawa et al., [13] & 49 & GSE1542 \\
\hline Liadaki et al., [19] & 39 & GSE1571 \\
\hline $\begin{array}{l}\text { Sandhu et al., } \\
\text { [25,26] }\end{array}$ & 49 & GSE60980 \\
\hline Janky et al., [14] & 118 & GSE62165 \\
\hline Yang et al., [37] & 69 & GSE62452 \\
\hline Moffit et al., [21] & 145 & GSE71729 \\
\hline Guttman et al., [11] & 80 & GSE8591 \\
\hline Lunardi., [20] & 53 & GSE55643 \\
\hline Zhang et al., & 45 & GSE28735 \\
\hline Wood et al., [28] & 36 & GSE1615 \\
\hline \multicolumn{2}{|c|}{ RNA } & tcga (April \\
\hline TCGA & 183 & Bailey et al \\
\hline Bailey et al., [1] & 69 & GSE79670 \\
\hline Kirby et al., [15] & 51 & \\
\hline
\end{tabular}

Enrichment Analysis, 4) Subtype Classifier Creation.

\subsubsection{Clustering}

Detailed by John et al., (2018) [40], the improvements of the M3C algorithm are all based upon the use of Monte-Carlo simulations. These are used to create a reference matrix. In brief, the simulations run multiple PCAs, whereby a random scores matrix of the $\mathrm{n}^{\text {th }}$ simulation is generated, and the eigenvector matrix is calculated. The simulated PCA random scores matrix and eigenvector matrix is then multiplied. These calculations are then repeated for the defined number of simulations. This results in a reference matrix that captures the associations between samples, but without the 'real' clusters.

This reference data set is then passed into the consensus clustering algorithm, as well as the original input data, and the two results are compared. The final output of M3C is essentially an improved consensus clustering result, that accounts for the null distribution (reference matrix).

In short, clustering finds samples of similarity and places them into groups without any similarity overlap between groups. The consensus clustering combines resampling with clustering, and integrates all the results from the various runs, in one final cluster result.

There are multiple different clustering and consensus clustering algorithms. The M3C algorithm calculates a novel metric, the Relative Cluster Stability Index (RCSI), obtained from real and simulated proportions of ambiguously clustered (PAC) scores. The RSCI provides a more accurate representation of stability across the distribution of $\mathrm{K}$, as the inherent stability bias is accounted for (See Figures $1 \mathrm{~A}$ and $1 \mathrm{C}$ ). The p-values for each $\mathrm{k}$ value are derived by comparing the simulated reference consensus clustering results and the real results. If these p-values are significant, then the null hypothesis that $\mathrm{K}=1$ (95\% confidence interval) is rejected. In other words, unlike the typical consensus clustering methods, the $\mathrm{M} 3 \mathrm{C}$ technique allows rejection of the hypothesis that there are no subtypes. In this study, M3C's default clustering loop was employed, partitioning around medoids (PAM) with Euclidean distance, with 100 iterations.

\subsubsection{Biological validation via Kaplan-Meier survival analysis}

Out of the expression cohort of 1013 individuals there were 303 patients with corresponding clinical data available. The KaplanMeier technique was employed, which calculates median survival (the shortest time at which the survival probability drops to $50 \%$ or lower) as described by Goel et al. [9], and the difference was

tested using the log-rank test. P-values of less than 0.05 were considered statistically significant. This was conducted using the survival R package and plotted with the survminer package [31] .

\subsubsection{Differential Expression}

The differential expression analysis was conducted, comparing one subtype to all other subtypes. The limma package 'lmFit' [24] function was used to calculate the fold changes and p-values of all genes. These are calculated by employing multiple linear models, on log-transformed expression data, for each comparison. To conduct these comparisons, multiple least squares regressions were employed. These can compare each subtype versus all other subtypes.

\subsubsection{Subtype Classifier}

A deep learning subtype classifier was created to enable the subtype identification of 'novel' PDAC expression samples. This classifier was built by employing the R version of the $\mathrm{H} 2 \mathrm{O}$ package 'autoML' function on the 500 most variable genes of the 1013 sample dataset. 
This dataset was randomly partitioned by $1 / 7$ th into training and test sets. The 'autoML' function is used to create multiple models fully automatically. This technique was set to generate 100 classification models, which included random forest models, XGBoost, deep learning, and stack ensemble models. The model with the lowest mean per class error rate (lowest average subtype identification error), a random grid search deep learning model, was selected as 'PDACNet'.

In brief, the deep learning subtype classifier is comprised of one hidden layer of 500 neurons that learns through the activation method known as rectifier with dropout (input dropout ratio $=0.15$, output dropout ratio $=0.4$ ), with hyperparameters optimised with random grid search (epochs $=46.44$ ). For further details of the deep learning model, see PDACNet file available at the GitHub link in the Data Availability section.

\section{RESULTS}

The results derived from analysis of the large PDAC cohort of 1013 patients. Principle Components Analyses Score and Scree plots (Appendix Figures $1 \& 2$ ). In Appendix Figures 1 and 2 there is an

A)

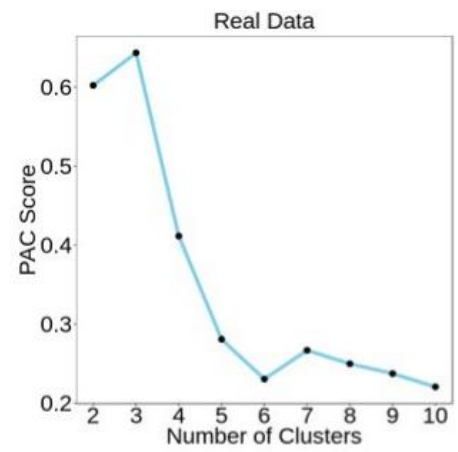

C)

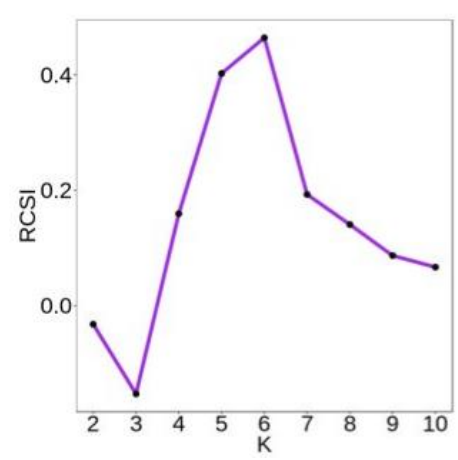

increase in variability in components 1 and 2, corresponding to the RNA sequencing and microarray data sets.

\subsection{M3C Identifies Six Clusters of PDAC}

We employed M3C on the dataset of 1013 patients, which resulted in 6 well-defined clusters.

The PAC score plot (Figure 1A) displays a sharp spike at $\mathrm{K}=6$, suggesting this is the optimal number of clusters. However, as with the CDF plot, the inherent stability bias can be seen here as it naturally tends towards lower values as $\mathrm{K}$ increases. Importantly, the traditional PAC score and Cophenetic coefficient plots cannot reject the null hypothesis $\mathrm{K}=1$.

The Cumulative Distribution Function (CDF) plot (Figure 1B), is a plot of the consensus matrices. The optimal value of $\mathrm{K}$ is the one with the flattest curve. Of note, in the CDF plot there is a noticeable bias of traditional consensus clustering techniques. This bias is based on the increase in stability as $\mathrm{K}$ increases for any given dataset.

The M3C approach outputs a Relative Cluster Stability Index (RCSI), which accounts for both PAC scores and simulated reference PAC scores. The RSCI is an improved metric for determining optimal $\mathrm{K}$ as it eliminates the inherent stability bias.

B)

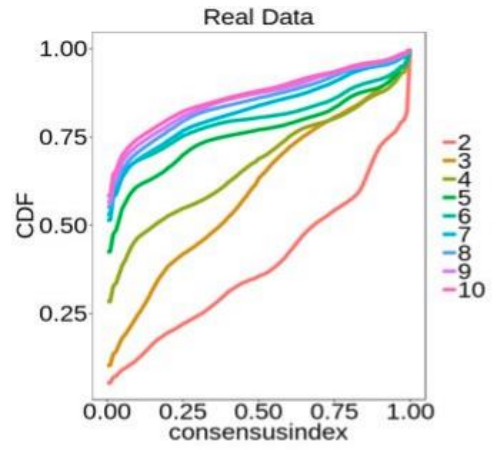

D)

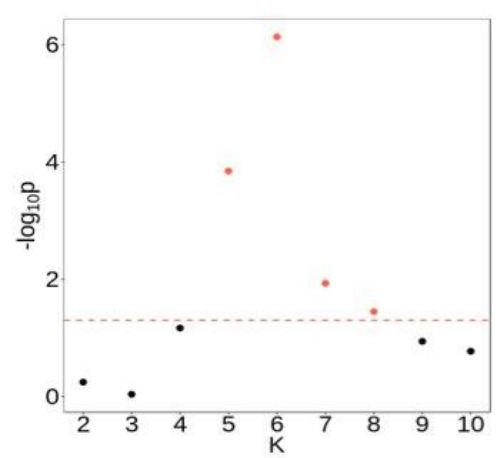

Figure 1 M3C Identification of 6 PDAC Clusters. A) PAC scores display a sharp downward spike at K=6. B) CDF plot shows flattening of the consensus index curve as K increases. C) RSCI shows a sharp upward spike at K=6. D) Plot of the P-values over $K=0: 10$. 
bioRxiv preprint doi: https://doi.org/10.1101/2019.12.16.870188; this version posted December 19, 2019. The copyright holder for this preprint (which was not certified by peer review) is the author/funder, who has granted bioRxiv a license to display the preprint in perpetuity. It is made available under aCC-BY-NC 4.0 International license.

The RSCI peaked at $\mathrm{K}=6$, confirming there are 6 clusters (Figure $1 \mathrm{C})$.

As part of $\mathrm{M} 3 \mathrm{C}$ analysis a beta p-value distribution is calculated. This is used to reject the null hypothesis that $\mathrm{K}=1$. If none of the $\mathrm{P}$ values are significant over a logical distribution of $K$ values, the null hypothesis is accepted. In this case, ranks 5:8 were of significance. The value of $\mathrm{K}=6$ was accepted. A Pearson's correlation was employed to check that these 6 clusters were not unfairly biased to the initial data sets, we also identified which proportions of the 14 datasets/batches the 6 subtypes comprise of. Appendix: Figure 3 and Table 3). Out of the 1013, 1002 samples fitted into the 6 clusters.

A direct comparison between the traditional NMF clustering technique and the $\mathrm{M} 3 \mathrm{C}$ clustering technique was also employed on the pancreatic cancer cohorts from Collisson et al., [3] and Bailey et al., [1] (Appendix Figures 4 \& 5). The PAC scores plots indicate that there are 3 and 4 clusters respectively, matching the results documents in their respective papers. However, for both studies, the RSCI metric would indicate that there are 4 and 8 clusters. Furthermore, the corresponding p-value distributions, with no significant values ( $>$ alpha $=0.05$ ), suggest that the clusters identified here are not particularly strong, hence the issues with reproducibility of these clusters.

A)

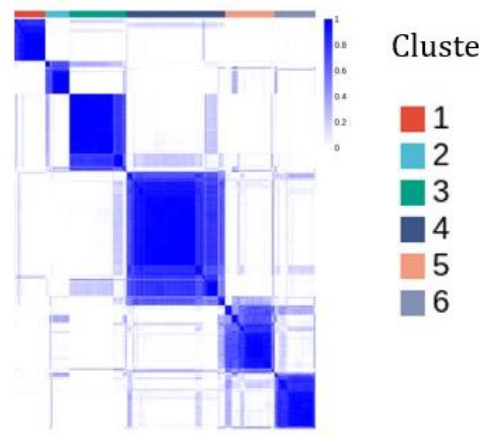

C)

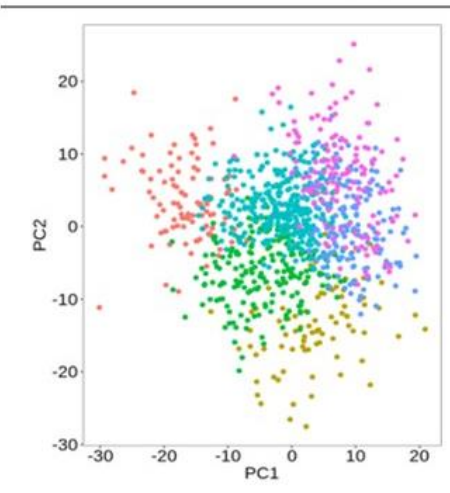

\subsection{Clinical Validation of PDAC subtypes}

From the merged dataset of 1013 samples, there are 303 samples with corresponding clinical data. The subtype labels and associated overall survival information were used to perform survival analysis. Figure 2A shows the consensus matrix of the 6 distinct subtypes. Figure 2B, a heatmap of the 2000 most variable genes, displays distinct expression profiles for each subtype. Figure $2 \mathrm{C}$ is PCA score plot (Components $1 \& 2$ ), of the six subtypes, whereby subtypes 5 and 6 have the most overlap. Figure 2D displays the Kaplan-Meier curves. While this was not significant, P-value= 0.063 , there is a clear trend that subtype/cluster 5 has the poorest survival outcome, and cluster 3 has the highest number of individuals at risk at time 0 .
B)
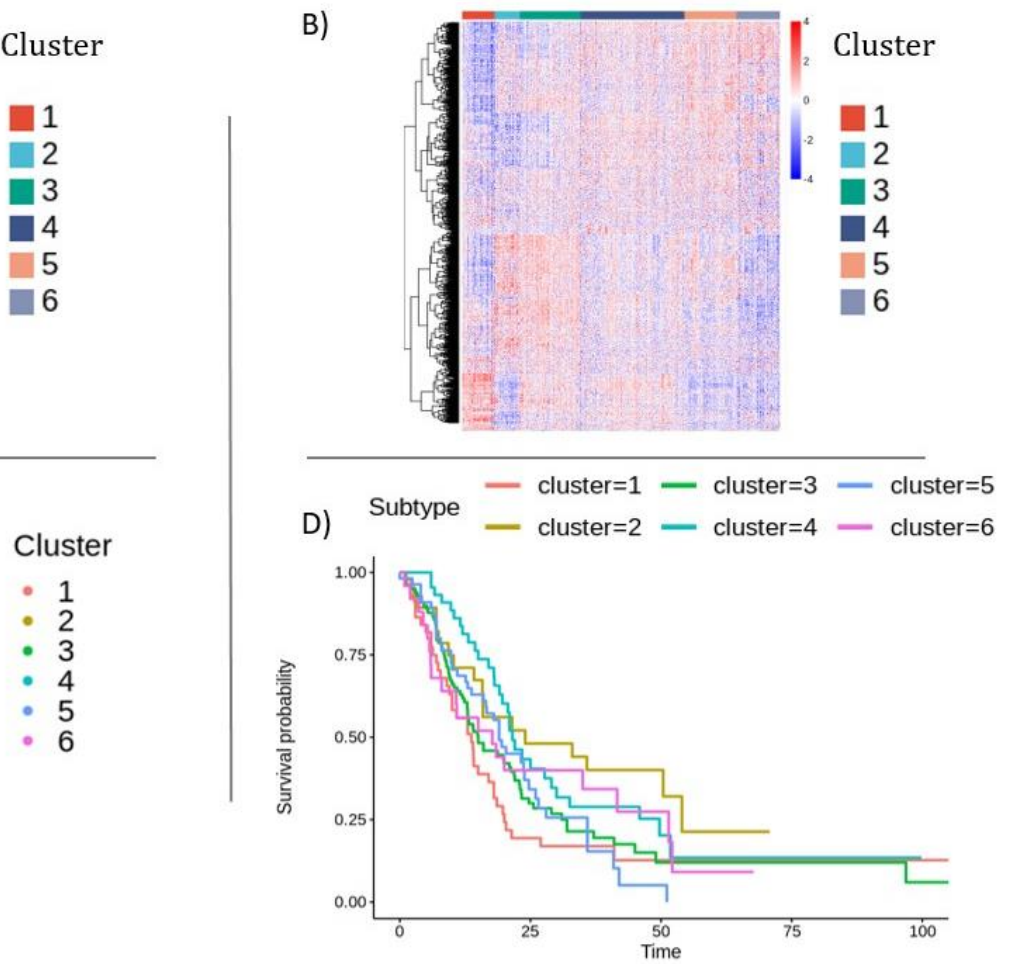

Figure 2 Clinical Validation of PDAC subtypes. A) Consensus matrix for the 6 distinct subtypes. B) Heatmap of the 2000 most variable genes, displaying distinct expression profiles for each subtype. C) PCA score plot (Components 1 \& 2) of the 6 subtypes, subtypes 5 and 6 have the most overlap. D) Kaplan-Meier curves showing differing survival trends for the identified subtypes $P$-value $=0.063$. 


\subsection{Functional Identification of PDA subtypes: Differential Expression and Literature Comparisons}

Differential expression analysis revealed distinct expression profiles for each subtype. Appendix Table 1 displays the 5 genes with the most significantly altered expression levels in each subtype. Full list of subtype specific genes is available at the GitHub link in the Data Availability section, as 'PDAC_Subtype_Specific_Genes.csv').

\subsection{Subtype Classifier: Selection}

In this study, 100 machine learning-based classifiers were created. Importantly the goal of this component was to create a wellperforming subtype classifier without the need for expert parameter tuning knowledge. H2O's autoML function is one of the simplest ways to do this, the minimal required inputs of the function are; an input training and test set, with outcome variable defined. Out of the 100 classifiers, the classifier with the lowest mean per class error was selected to be further analysed (PDACNet). Notably the logarithmic loss result is greater than 1 , this combined with the low mean per class error indicates that the model is highly confident about an incorrect subtype classification. Table 2 displays the results of the top 5 classifiers, ordered by the mean per class error. Appendix Table 2 displays the prediction errors when the PDACNet was applied on the test set, the partitioned 1/7th of the 1002 samples that fitted into one of the 6 clustes . For full information regarding parameters of the deep learning model that has the lowest mean per class error, see the PDACNet file available at the GitHub link in the Data Availability section. The important takeaway here is that subtype classifiers can enable the subtype classification on 'novel' PDAC expression samples/cohorts that are outside of this study. This enables all the improvements from the information captured by the large cohort and application of $\mathrm{M} 3 \mathrm{C}$ to be transferred over when trying to distinguish the subtypes of only a few samples. Applying a subtyping technique to a few samples or a small cohort would provide poorly clustered results.

\section{DISCUSSION}

This work describes an improved workflow for gene expression subtyping studies. This workflow includes rapid creation of expression datasets from both RNA-Sequencing and Microarray datasets. These large datasets can then be subtyped using M3C, which as previously mentioned removes the inherent stability bias and can disprove the null hypothesis that $\mathrm{K}=1$. Biological and clinical validation can be employed by a) Distinguishing differentially expressed genes in each subtype, b) Distinguishing distinct survival times via survival-analysis. Lastly, classifier creation with subtype annotations is a novel way to mimic an unsupervised subtyping study on distinct datasets.
Table 2 The top 5 Subtype Classifiers. Ordered by the mean per class error. The top model is 'DeepLearning_Drid_Search_Model_1'

\begin{tabular}{|l|l|l|l|}
\hline Model id & $\begin{array}{l}\text { Mean per } \\
\text { Class error }\end{array}$ & $\begin{array}{l}\text { Log } \\
\text { Loss }\end{array}$ & $\begin{array}{l}\text { Root mean } \\
\text { standard error }\end{array}$ \\
\hline $\begin{array}{l}\text { DeepLearning_Grid_S } \\
\text { earch_Model_1 }\end{array}$ & 0.140 & 1.09 & 0.385 \\
\hline $\begin{array}{l}\text { DeepLearning_Grid_S } \\
\text { earch_Model_8 }\end{array}$ & 0.146 & 1.52 & 0.380 \\
\hline $\begin{array}{l}\text { Stacked_Ensemble_ } \\
\text { Best_Of_Family }\end{array}$ & 0.157 & 0.452 & 0.355 \\
\hline $\begin{array}{l}\text { Stacked_Ensemble_ } \\
\text { All_Models }\end{array}$ & 0.161 & 0.526 & 0.404 \\
\hline $\begin{array}{l}\text { DeepLearning_Grid_S } \\
\text { earch_Model_8 }\end{array}$ & 0.173186 & 1.03 & 0.390 \\
\hline
\end{tabular}

\subsection{Alternative Methods to Increase Cohort Size}

This study focused on a dataset of 1013 PDAC patients, whereby expression data was derived cancer tissue. However, there are multiple studies which have included expression values from tissue and other sources e.g. tumour derived cell lines. While this may increase the statistical power, and robustness, there are reports which indicate not all tumoral cell lines accurately represent solid tumours. This issue was first distinguished in a lung cancer subtyping study, whereby out of the 11 cell lines representing lung adenocarcinomas, none of them formed clusters with tumoral adenocarcinomas [33].

Along the lines of including samples from other sources, other studies have focused on specific cancers, and not a specific type of histopathology. For example, Bailey et.al., [1] performed a subtyping study on six histopathological types of pancreatic cancer. This included: pancreatic adenocarcinomas, adenosquamus, acinar cell carcinoma, intraductal papillary mucinous neoplasm, and four other rare pancreatic tumours. However, as indicated by the silhouettes the sample with the highest stability in their cluster 1 was Acinar cell carcinoma, and in cluster 3 was an adenosquamous carcinoma. Similarly, all 11 intraductal papillary neoplasms were unstable with silhouette widths $<0.1$. It appears to identify subtypes accurately on one histopathological type at a time. Intentionally or unintentionally subtyping (through pathological identification errors) different histopathological tumours may also be contributing to the challenge of reproducing subtyping results. 


\subsection{Molecular Discussion of Subtypes}

Class 1 included AOX1, FLRT2, SLC1A2, GAMT and KCNJ5. AOX1 is known for being the precursor of a xenobiotic metabolising enzyme, and Sigruener et al., [28] has previously proven downregulation in pancreatic cancer, with its cellular functions revolving around lipid efflux and phagocytosis in hepatocytes. Expression of KCNJ5 has also previously been shown to be downregulated in PDAC compared to controls [30]. This gene is known of the potassium inwardly rectifying channel family.

Interestingly, classes 2 and 3 appear to have the same 5 genes that have the most significantly altered expressions. In class 2 they are upregulated and in class 3 they are downregulated. GAMT which has altered expression in classes 1, 2, and 3 is known to be involved in p53-dependent apoptosis and is particularly important for cell apoptosis and survival under nutrient deficient conditions [39]. P2RX1 gene is the precursor of an ATP-gated nonselective ion channel [16]. NUCB2 has been reported to inhibit apoptosis of pancreatic cells.

In class 4 EPB41L4B is the most significant gene, this plays a role in the proliferation of epithelial cells and matches reports of its downregulation in PDAC [35]. In class 5, the most differentially expressed gene AP1M2 has also been previously reported to be differentially expressed in PDAC stromal tissue [23].

A study by Zhao et al. [38] also identified 6 PDAC subtypes. Interestingly their gene expression analysis was not too dissimilar to this study. They displayed a subtype with carbohydrate metabolism gene expression alterations, such as ALDOB, CA2, NPC1L1 and PGC. Another subtype identified by Zhao et al, appeared to have more alterations in Cell proliferation and epithelium-associated genes, such as CCNB2, CDKN2A, SFN, UBE2C, SPRR3, DHRS9 and CRABP2. GREM1, MFAP5, COL12A1, COL10A1, COL8A1 and other collagen or ECMrelated genes. They also identified a subtype with Immune related genes alterations such as CCL, CCR7 and CD gene families. Neuroendocrine-associated genes such as PAX6, IAPP, G6PC2, ABCC8 and ZBTB16 are highly expressed in another subtype. Lastly, Zhao et al. identified a subtype with multiple gene alteration differences involved in lipid and protein metabolism CLPS, PLA2G1B, CEL, ALB, CPA1, CPB1, CTRL, SLC3A1, PRSS3 and ANPEP. Whilst Zhao's study was rather comprehensive with their gene set enrichment analysis, the original differential expression was based upon inherent differences between subtypes, an alternative approach would compare subtypes to healthy controls. In this case comparing gene expression profiles here is a challenge and would require full data sets of expressed genes to be available.

Overall, differential expression genes are to be expected all have either a function relating to increased cancer likelihood or be attributed dysfunctional pancreatic cells (e.g GAMT and its relationship with $\mathrm{p} 53$, and $\mathrm{P} 2 \mathrm{RX} 1$ and its ion channel dysfunction).

\subsection{Overview}

To enable the use of our classification on new cohorts we made a subtyping classifier, based upon a large multi-centred dataset. Unlike traditional classification studies, whereby the typical aim is to discover a series of predictive biomarkers, the goal of the classifier creation was to: a) facilitate our subtyping of PDAC on novel cohorts, b) Develop a pipeline that could be easily applied on a different expression cohort, of a different cancer, in a matter of hours (hence no manual fine tuning of parameters in this case). Despite our creation of the multi-centred dataset and $\mathrm{M} 3 \mathrm{C}$ results, RSCI and p-value for 6 clusters, it is still possible that the clusters do not fit all PDAC individuals. Hence the classifier could possibly misidentify rare PAC types. Ideally with the widening access of sequencing technologies, our study will be repeated with a larger cohort resembling the PDAC population more accurately.

As well as advances in the amount of expression data available, there will likely be advances in available associated omics data. Expression data does not capture the effects tumoral mutations have on downstream functionality. In other words, a gene could be highly expressed but downstream non-functional. There are multiple data sources which could combine with mRNAexpression data to improve subtyping information capacity. Kuijer et al., [18] suggested that somatic mutation-based subtyping can provide novel insights. Typically, clinical trials use single gene mutations as guidelines. Unique patterns of somatic mutation information combined with mRNA expression subtyping may provide an extra layer to identify individuals who will respond optimally (and individuals who will not respond) to certain treatments. The iCluster algorithm was built to identify novel subtypes by integrating DNA copy number changes and gene expression, which has distinguished novel subtypes in lung and breast cancer [27]. Notably iCluster has been applied to a cohort of 363 pancreatic hepatocellular carcionmas[36], identifying 3 subtypes. However, iCluster is based upon K-means clustering, which is also subject to the inherent stability bias. Perhaps, the addition of a reference matrix and Monte-carlo simulations to Kmeans clustering could be an integral step in this case.

\section{CONCLUSION}

In conclusion, we have developed a novel approach to subtyping expression data. This includes the generation of large cohorts, use of $\mathrm{M} 3 \mathrm{C}, \mathrm{DE}$ analysis, and classifier creation. Importantly, our robust distinction of six PDAC subtypes has set a benchmark for future PDAC subtyping studies. This could be a foundation to discovering novel PDAC personalized therapies and improving survival time predictions. 


\section{MATERIAL \& DATA AVAILABILITY:}

All data, including the 1013 patient cohort, relevant scripts and PDACNet is available at: https://github.com/KristoferLintonReid/Enhanced-CancerSubtyping-

\section{ACKNOWLEDGMENTS}

The authors would like to thank everyone at and involved with Cambridge Cancer Genomics whom made this project possible and offered insightful constructive feedback throughout this study.

\section{REFERENCES}

[1] Peter Bailey, David K. Chang, Katia Nones, Amber L. Johns, Ann-Marie Patch, Marie-Claude Gingras, David K. Miller, Angelika N. Christ, Tim J. C. Bruxner, Michael C. Quinn, Craig Nourse, L. Charles Murtaugh, Ivon Harliwong, Senel Idrisoglu, Suzanne Manning, Ehsan Nourbakhsh, Shivangi Wani, Lynn Fink, Oliver Holmes, Venessa Chin, Matthew J. Anderson, Stephen Kazakoff, Conrad Leonard, Felicity Newell, Nick Waddell, Scott Wood, Qinying Xu, Peter J. Wilson, Nicole Cloonan, Karin S. Kassahn, Darrin Taylor, Kelly Quek, Alan Robertson, Lorena Pantano, Laura Mincarelli, Luis N. Sanchez, Lisa Evers, Jianmin Wu, Mark Pinese, Mark J. Cowley, Marc D. Jones, Emily K. Colvin, Adnan M. Nagrial, Emily S. Humphrey, Lorraine A. Chantrill, Amanda Mawson, Jeremy Humphris, Angela Chou, Marina Pajic, Christopher J. Scarlett, Andreia V. Pinho, Marc Giry-Laterriere, Ilse Rooman, Jaswinder S. Samra, James G. Kench, Jessica A. Lovell, Neil D. Merrett, Christopher W. Toon, Krishna Epari, Nam Q. Nguyen, Andrew Barbour, Nikolajs Zeps, Kim Moran-Jones, Nigel B. Jamieson, Janet S. Graham, Fraser Duthie, Karin Oien, Jane Hair, Robert Grützmann, Anirban Maitra, Christine A. Iacobuzio-Donahue, Christopher L. Wolfgang, Richard A. Morgan, Rita T. Lawlor, Vincenzo Corbo, Claudio Bassi, Borislav Rusev, Paola Capelli, Roberto Salvia, Giampaolo Tortora, Debabrata Mukhopadhyay, Gloria M. Petersen, Australian Pancreatic Cancer Genome Initiative, Donna M. Munzy, William E. Fisher, Saadia A. Karim, James R. Eshleman, Ralph H. Hruban, Christian Pilarsky, Jennifer P. Morton, Owen J. Sansom, Aldo Scarpa, Elizabeth A. Musgrove, Ulla-Maja Hagbo Bailey, Oliver Hofmann, Robert L. Sutherland, David A. Wheeler, Anthony J. Gill, Richard A. Gibbs, John V. Pearson, Nicola Waddell, Andrew V. Biankin, and Sean M. Grimmond. 2016. Genomic analyses identify molecular subtypes of pancreatic cancer. Nature 531, 7592 (March 2016), 47-52. DOI:https://doi.org/10.1038/nature16965

[2] Clara Bodelon, J. Keith Killian, Joshua N. Sampson, William F. Anderson, Rayna Matsuno, Louise A. Brinton, Jolanta Lissowska, Michael S. Anglesio, David D. L. Bowtell, Jennifer A.
Doherty, Susan J. Ramus, Aline Talhouk, Mark Sherman, and Nicolas Wentzensen. 2019. Molecular classification of epithelial ovarian cancer based on methylation profiling: evidence for survival heterogeneity. Clin Cancer Res (January 2019), clincanres.3720.2018. DOI:https://doi.org/10.1158/10780432.CCR-18-3720

[3] Eric A. Collisson, Anguraj Sadanandam, Peter Olson, William J. Gibb, Morgan Truitt, Shenda Gu, Janine Cooc, Jennifer Weinkle, Grace E. Kim, Lakshmi Jakkula, Heidi S. Feiler, Andrew H. Ko, Adam B. Olshen, Kathleen L. Danenberg, Margaret A. Tempero, Paul T. Spellman, Douglas Hanahan, and Joe W. Gray. 2011. Subtypes of pancreatic ductal adenocarcinoma and their differing responses to therapy. Nat. Med. 17, 4 (April 2011), 500-503. DOI:https://doi.org/10.1038/nm.2344 [4] Maria Vittoria Dieci, Enrico Orvieto, Massimo Dominici, PierFranco Conte, and Valentina Guarneri. 2014. Rare breast cancer subtypes: histological, molecular, and clinical peculiarities. Oncologist 19, 8 (August 2014), 805-813. DOI:https://doi.org/10.1634/theoncologist.2014-0108 [5] Timothy R. Donahue, Linh M. Tran, Reginald Hill, Yunfeng Li, Anne Kovochich, Joseph H. Calvopina, Sanjeet G. Patel, Nanping Wu, Antreas Hindoyan, James J. Farrell, Xinmin Li, David W. Dawson, and Hong Wu. 2012. Integrative survivalbased molecular profiling of human pancreatic cancer. Clin. Cancer Res. 18, 5 (March 2012), 1352-1363.

DOI:https://doi.org/10.1158/1078-0432.CCR-11-1539

[6] Geoffroy Dubourg-Felonneau, Timothy Cannings, Fergal Cotter, Hannah Thompson, Nirmesh Patel, John W. Cassidy, and Harry W. Clifford. 2018. A Framework for Implementing Machine Learning on Omics Data. arXiv:1811.10455 [cs, q-bio, stat] (November 2018). Retrieved October 20, 2019 from http://arxiv.org/abs/1811.10455

[7] Jennifer M. Franks, Guoshuai Cai, and Michael L. Whitfield. 2018. Feature specific quantile normalization enables cross-platform classification of molecular subtypes using gene expression data. Bioinformatics 34, 11 (01 2018), 1868-1874. DOI:https://doi.org/10.1093/bioinformatics/bty026

[8] Renaud Gaujoux and Cathal Seoighe. 2010. A flexible $\mathrm{R}$ package for nonnegative matrix factorization. $B M C$

Bioinformatics 11, 1 (July 2010), 367.

DOI:https://doi.org/10.1186/1471-2105-11-367

[9] Manish Kumar Goel, Pardeep Khanna, and Jugal Kishore. 2010. Understanding survival analysis: Kaplan-Meier estimate. Int J Ayurveda Res 1, 4 (2010), 274-278. DOI:https://doi.org/10.4103/0974-7788.76794

[10] Justin Guinney, Rodrigo Dienstmann, Xin Wang, Aurélien de Reyniès, Andreas Schlicker, Charlotte Soneson, Laetitia Marisa, Paul Roepman, Gift Nyamundanda, Paolo Angelino, Brian M. Bot, Jeffrey S. Morris, Iris M. Simon, Sarah Gerster, Evelyn Fessler, Felipe De Sousa E. Melo, Edoardo Missiaglia, Hena Ramay, David Barras, Krisztian Homicsko, Dipen Maru, Ganiraju C. Manyam, Bradley Broom, Valerie Boige, Beatriz Perez-Villamil, Ted Laderas, Ramon Salazar, Joe 
W. Gray, Douglas Hanahan, Josep Tabernero, Rene Bernards, Stephen H. Friend, Pierre Laurent-Puig, Jan Paul Medema, Anguraj Sadanandam, Lodewyk Wessels, Mauro Delorenzi, Scott Kopetz, Louis Vermeulen, and Sabine Tejpar. 2015. The consensus molecular subtypes of colorectal cancer. Nature Medicine 21, 11 (November 2015), 1350-1356.

DOI:https://doi.org/10.1038/nm.3967

[11] Mitchell Guttman, Carolyn Mies, Katarzyna DudyczSulicz, Sharon J. Diskin, Don A. Baldwin, Christian J. Stoeckert, and Gregory R. Grant. 2007. Assessing the significance of conserved genomic aberrations using high resolution genomic microarrays. PLoS Genet. 3, 8 (August 2007), e143.

DOI:https://doi.org/10.1371/journal.pgen.0030143

[12] Åslaug Helland, Michael S. Anglesio, Joshy George, Prue A. Cowin, Cameron N. Johnstone, Colin M. House, Karen E. Sheppard, Dariush Etemadmoghadam, Nataliya Melnyk, Anil K. Rustgi, Wayne A. Phillips, Hilde Johnsen, Ruth Holm, Gunnar B. Kristensen, Michael J. Birrer, Australian Ovarian Cancer Study Group, Richard B. Pearson, Anne-Lise Børresen-Dale, David G. Huntsman, Anna deFazio, Chad J. Creighton, Gordon K. Smyth, and David D. L. Bowtell. 2011. Deregulation of MYCN, LIN28B and LET7 in a molecular subtype of aggressive high-grade serous ovarian cancers. PLoS ONE 6, 4 (April 2011), e18064. DOI:https://doi.org/10.1371/journal.pone.0018064

[13] Madoka Ishikawa, Koji Yoshida, Yoshihiro Yamashita, Jun Ota, Shuji Takada, Hiroyuki Kisanuki, Koji Koinuma, Young Lim Choi, Ruri Kaneda, Toshiyasu Iwao, Kiichi Tamada, Kentaro Sugano, and Hiroyuki Mano. 2005. Experimental trial for diagnosis of pancreatic ductal carcinoma based on gene expression profiles of pancreatic ductal cells. Cancer Sci. 96, 7 (July 2005), 387-393. DOI:https://doi.org/10.1111/j.13497006.2005.00064.x

[14] Rekin's Janky, Maria Mercedes Binda, Joke Allemeersch, Anke Van den broeck, Olivier Govaere, Johannes V. Swinnen, Tania Roskams, Stein Aerts, and Baki Topal. 2016. Prognostic relevance of molecular subtypes and master regulators in pancreatic ductal adenocarcinoma. BMC Cancer 16, (August 2016). DOI:https://doi.org/10.1186/s12885-016-2540-6

[15] W. Evan Johnson, Cheng Li, and Ariel Rabinovic. 2007. Adjusting batch effects in microarray expression data using empirical Bayes methods. Biostatistics 8, 1 (January 2007), 118127. DOI:https://doi.org/10.1093/biostatistics/kxj037

[16] Karina Kaczmarek-Hájek, Eva Lörinczi, Ralf Hausmann, and Annette Nicke. 2012. Molecular and functional properties of $\mathrm{P} 2 \mathrm{X}$ receptors--recent progress and persisting challenges. Purinergic Signal. 8, 3 (September 2012), 375-417. DOI:https://doi.org/10.1007/s11302-012-9314-7

[17] Marie K. Kirby, Ryne C. Ramaker, Jason Gertz, Nicholas S. Davis, Bobbi E. Johnston, Patsy G. Oliver, Katherine C. Sexton, Edward W. Greeno, John D. Christein, Martin J. Heslin, James A. Posey, William E. Grizzle, Selwyn M. Vickers, Donald J. Buchsbaum, Sara J. Cooper, and Richard M. Myers. 2016. RNA sequencing of pancreatic adenocarcinoma tumors yields novel expression patterns associated with long-term survival and reveals a role for ANGPTL4. Mol Oncol 10, 8 (2016), 1169-1182. DOI:https://doi.org/10.1016/j.molonc.2016.05.004

[18] Marieke Lydia Kuijjer, Joseph Nathaniel Paulson, Peter Salzman, Wei Ding, and John Quackenbush. 2018. Cancer subtype identification using somatic mutation data. Br. J. Cancer 118, 11 (2018), 1492-1501. DOI:https://doi.org/10.1038/s41416018-0109-7

[19] K. Liadaki, A. T. Kho, D. Sanoudou, J. Schienda, A. Flint, A. H. Beggs, I. S. Kohane, and L. M. Kunkel. 2005. Side population cells isolated from different tissues share transcriptome signatures and express tissue-specific markers. Exp. Cell Res. 303, 2 (February 2005), 360-374.

DOI:https://doi.org/10.1016/j.yexcr.2004.10.011

[20] Serena Lunardi, Nigel B. Jamieson, Su Yin Lim, Kristin L. Griffiths, Manuela Carvalho-Gaspar, Osama Al-Assar, Sabira Yameen, Ross C. Carter, Colin J. McKay, Gabriele Spoletini, Stefano D’Ugo, Michael A. Silva, Owen J. Sansom, Klaus-Peter Janssen, Ruth J. Muschel, and Thomas B. Brunner. 2014. IP10/CXCL10 induction in human pancreatic cancer stroma influences lymphocytes recruitment and correlates with poor survival. Oncotarget 5, 22 (November 2014), 11064-11080. DOI:https://doi.org/10.18632/oncotarget.2519

[21] Richard A. Moffitt, Raoud Marayati, Elizabeth L. Flate, Keith E. Volmar, S. Gabriela Herrera Loeza, Katherine A. Hoadley, Naim U. Rashid, Lindsay A. Williams, Samuel C. Eaton, Alexander H. Chung, Jadwiga K. Smyla, Judy M. Anderson, Hong Jin Kim, David J. Bentrem, Mark S. Talamonti, Christine A. Iacobuzio-Donahue, Michael A. Hollingsworth, and Jen Jen Yeh. 2015. Virtual microdissection identifies distinct tumor- and stroma-specific subtypes of pancreatic ductal adenocarcinoma. Nat. Genet. 47, 10 (October 2015), 1168-1178. DOI:https://doi.org/10.1038/ng.3398

[22] Gonzalo Durán Pacheco, Jan Hattendorf, John M. Colford, Daniel Mäusezahl, and Thomas Smith. 2009.

Performance of analytical methods for overdispersed counts in cluster randomized trials: Sample size, degree of clustering and imbalance. Statistics in Medicine 28, 24 (2009), 2989-3011. DOI:https://doi.org/10.1002/sim.3681

[23] Christian Pilarsky, Ole Ammerpohl, Bence Sipos, Edgar Dahl, Arndt Hartmann, Axel Wellmann, Till Braunschweig, Matthias Löhr, Ralf Jesenofsky, Ralf Jesnowski, Helmut Friess, Moritz Nicolas Wente, Glen Kristiansen, Beatrix Jahnke, Axel Denz, Felix Rückert, Hans K. Schackert, Günter Klöppel, Holger Kalthoff, Hans Detlev Saeger, and Robert Grützmann. 2008. Activation of Wnt signalling in stroma from pancreatic cancer identified by gene expression profiling. J. Cell. Mol. Med. 12, 6B (December 2008), 2823-2835. DOI:https://doi.org/10.1111/j.1582-4934.2008.00289.x [24] Matthew E. Ritchie, Belinda Phipson, Di Wu, Yifang Hu, Charity W. Law, Wei Shi, and Gordon K. Smyth. 2015. limma powers differential expression analyses for RNA- 
sequencing and microarray studies. Nucleic Acids Res. 43, 7 (April 2015), e47. DOI:https://doi.org/10.1093/nar/gkv007

[25] V. Sandhu, I. M. Bowitz Lothe, K. J. Labori, O. C. Lingjærde, T. Buanes, A. M. Dalsgaard, M. L. Skrede, J. Hamfjord, T. Haaland, T. J. Eide, A. -L. Børresen-Dale, T. Ikdahl, and E. H. Kure. 2015. Molecular signatures of mRNAs and miRNAs as prognostic biomarkers in pancreatobiliary and intestinal types of periampullary adenocarcinomas. Molecular Oncology 9, 4 (April 2015), 758-771.

DOI:https://doi.org/10.1016/j.molonc.2014.12.002

[26] V. Sandhu, I. M. Bowitz Lothe, K. J. Labori, M. L. Skrede, J. Hamfjord, A. M. Dalsgaard, T. Buanes, G. Dube, M. M. Kale, S. Sawant, U. Kulkarni-Kale, A.-L. Børresen-Dale, O. C. Lingjærde, and E. H. Kure. 2016. Differential expression of miRNAs in pancreatobiliary type of periampullary adenocarcinoma and its associated stroma. Mol Oncol 10, 2 (February 2016), 303-316. DOI:https://doi.org/10.1016/j.molonc.2015.10.011

[27] Ronglai Shen, Adam B. Olshen, and Marc Ladanyi. 2009. Integrative clustering of multiple genomic data types using a joint latent variable model with application to breast and lung cancer subtype analysis. Bioinformatics 25, 22 (November 2009), 2906-2912. DOI:https://doi.org/10.1093/bioinformatics/btp543

[28] A. Sigruener, C. Buechler, E. Orsó, A. Hartmann, P. J. Wild, L. Terracciano, M. Roncalli, S. R. Bornstein, and G. Schmitz. 2007. Human aldehyde oxidase 1 interacts with ATPbinding cassette transporter- 1 and modulates its activity in hepatocytes. Horm. Metab. Res. 39, 11 (November 2007), 781789. DOI:https://doi.org/10.1055/s-2007-992129

[29] Tuan Zea Tan, Qing Hao Miow, Ruby Yun-Ju Huang, Meng Kang Wong, Jieru Ye, Jieying Amelia Lau, Meng Chu Wu, Luqman Hakim Bin Abdul Hadi, Richie Soong, Mahesh Choolani, Ben Davidson, Jahn M Nesland, Ling-Zhi Wang, Noriomi Matsumura, Masaki Mandai, Ikuo Konishi, Boon-Cher Goh, Jeffrey T Chang, Jean Paul Thiery, and Seiichi Mori. 2013. Functional genomics identifies five distinct molecular subtypes with clinical relevance and pathways for growth control in epithelial ovarian cancer. EMBO Mol Med 5, 7 (July 2013), 983998. DOI:https://doi.org/10.1002/emmm.201201823

[30] Yuchen Tang, Zixiang Zhang, Yaocheng Tang, Xinyu Chen, and Jian Zhou. 2018. Identification of potential target genes in pancreatic ductal adenocarcinoma by bioinformatics analysis.

Oncol Lett 16, 2 (August 2018), 2453-2461.

DOI:https://doi.org/10.3892/ol.2018.8912

[31] Terry M. Therneau and Patricia M. Grambsch. 2000.

The Cox Model. In Modeling Survival Data: Extending the Cox

Model, Terry M. Therneau and Patricia M. Grambsch (eds.).

Springer New York, New York, NY, 39-77.

DOI:https://doi.org/10.1007/978-1-4757-3294-8_3

[32] Richard W. Tothill, Anna V. Tinker, Joshy George, Robert Brown, Stephen B. Fox, Stephen Lade, Daryl S. Johnson, Melanie K. Trivett, Dariush Etemadmoghadam, Bianca Locandro, Nadia Traficante, Sian Fereday, Jillian A. Hung, Yoke-Eng
Chiew, Izhak Haviv, Australian Ovarian Cancer Study Group, Dorota Gertig, Anna DeFazio, and David D. L. Bowtell. 2008. Novel molecular subtypes of serous and endometrioid ovarian cancer linked to clinical outcome. Clin. Cancer Res. 14, 16 (August 2008), 5198-5208. DOI:https://doi.org/10.1158/10780432.CCR-08-0196

[33] Carl Virtanen, Yuichi Ishikawa, Daisuke Honjoh, Mami Kimura, Miyuki Shimane, Tatsu Miyoshi, Hitoshi Nomura, and Michael H. Jones. 2002. Integrated classification of lung tumors and cell lines by expression profiling. Proc. Natl. Acad. Sci. U.S.A. 99, 19 (September 2002), 12357-12362. DOI:https://doi.org/10.1073/pnas.192240599

[34] Nicola Waddell, Marina Pajic, Ann-Marie Patch, David K. Chang, Karin S. Kassahn, Peter Bailey, Amber L. Johns, David Miller, Katia Nones, Kelly Quek, Michael C. J. Quinn, Alan J. Robertson, Muhammad Z. H. Fadlullah, Tim J. C. Bruxner, Angelika N. Christ, Ivon Harliwong, Senel Idrisoglu, Suzanne Manning, Craig Nourse, Ehsan Nourbakhsh, Shivangi Wani, Peter J. Wilson, Emma Markham, Nicole Cloonan, Matthew J. Anderson, J. Lynn Fink, Oliver Holmes, Stephen H. Kazakoff, Conrad Leonard, Felicity Newell, Barsha Poudel, Sarah Song, Darrin Taylor, Nick Waddell, Scott Wood, Qinying Xu, Jianmin Wu, Mark Pinese, Mark J. Cowley, Hong C. Lee, Marc D. Jones, Adnan M. Nagrial, Jeremy Humphris, Lorraine A. Chantrill, Venessa Chin, Angela M. Steinmann, Amanda Mawson, Emily S. Humphrey, Emily K. Colvin, Angela Chou, Christopher J. Scarlett, Andreia V. Pinho, Marc Giry-Laterriere, Ilse Rooman, Jaswinder S. Samra, James G. Kench, Jessica A. Pettitt, Neil D. Merrett, Christopher Toon, Krishna Epari, Nam Q. Nguyen, Andrew Barbour, Nikolajs Zeps, Nigel B. Jamieson, Janet S. Graham, Simone P. Niclou, Rolf Bjerkvig, Robert Grützmann, Daniela Aust, Ralph H. Hruban, Anirban Maitra, Christine A. Iacobuzio-Donahue, Christopher L. Wolfgang, Richard A. Morgan, Rita T. Lawlor, Vincenzo Corbo, Claudio Bassi, Massimo Falconi, Giuseppe Zamboni, Giampaolo Tortora, Margaret A. Tempero, Australian Pancreatic Cancer Genome Initiative, Anthony J. Gill, James R. Eshleman, Christian Pilarsky, Aldo Scarpa, Elizabeth A. Musgrove, John V. Pearson, Andrew V. Biankin, and Sean M. Grimmond. 2015. Whole genomes redefine the mutational landscape of pancreatic cancer. Nature 518, 7540 (February 2015), 495-501.

DOI:https://doi.org/10.1038/nature14169

[35] Stephanie J. Walker, Laura M. Selfors, Ben L. Margolis, and Joan S. Brugge. 2018. CRB3 and the FERM protein EPB41L4B regulate proliferation of mammary epithelial cells through the release of amphiregulin. PLOS ONE 13, 11 (2018), e0207470. DOI:https://doi.org/10.1371/journal.pone.0207470

[36] David A. Wheeler and Lewis R. Roberts. 2017. Comprehensive and Integrative Genomic Characterization of Hepatocellular Carcinoma. Cell 169, 7 (June 2017), 13271341.e23. DOI:https://doi.org/10.1016/j.cell.2017.05.046 [37] Shouhui Yang, Peijun He, Jian Wang, Aaron Schetter, Wei Tang, Naotake Funamizu, Katsuhiko Yanaga, Tadashi 
bioRxiv preprint doi: https://doi.org/10.1101/2019.12.16.870188; this version posted December 19, 2019. The copyright holder for this preprint (which was not certified by peer review) is the author/funder, who has granted bioRxiv a license to display the preprint in perpetuity. It is made available under aCC-BY-NC 4.0 International license.

Uwagawa, Abhay R. Satoskar, Jochen Gaedcke, Markus Bernhardt, B. Michael Ghadimi, Matthias M. Gaida, Frank Bergmann, Jens Werner, Thomas Ried, Nader Hanna, H. Richard Alexander, and S. Perwez Hussain. 2016. A Novel MIF Signaling Pathway Drives the Malignant Character of Pancreatic Cancer by Targeting NR3C2. Cancer Res. 76, 13 (01 2016), 3838-3850. DOI:https://doi.org/10.1158/0008-5472.CAN-15-2841

[38] Lan Zhao, Hongya Zhao, and Hong Yan. 2018. Gene expression profiling of 1200 pancreatic ductal adenocarcinoma reveals novel subtypes. BMC Cancer 18, 1 (May 2018), 603. DOI:https://doi.org/10.1186/s12885-018-4546-8

[39] Yan Zhu and Carol Prives. 2009. p53 and Metabolism: The GAMT Connection. Molecular Cell 36, 3 (November 2009), 351-352. DOI:https://doi.org/10.1016/j.molcel.2009.10.026

[40] M3C: A Monte Carlo reference-based consensus clustering algorithm | bioRxiv. Retrieved October 20, 2019 from https://www.biorxiv.org/content/10.1101/377002v1 
bioRxiv preprint doi: https://doi.org/10.1101/2019.12.16.870188; this version posted December 19, 2019. The copyright holder for this preprint (which was not certified by peer review) is the author/funder, who has granted bioRxiv a license to display the preprint in perpetuity. It is made available under aCC-BY-NC 4.0 International license.

A)

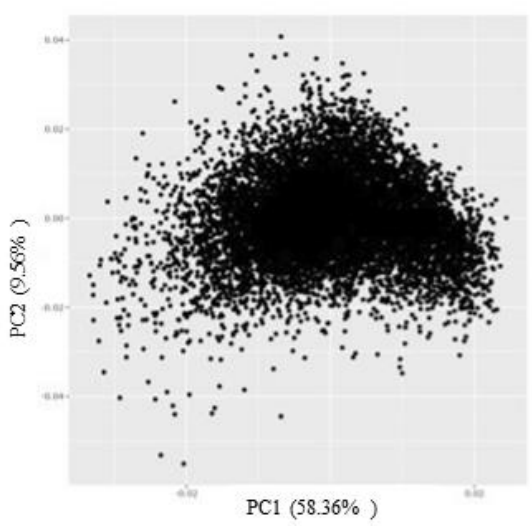

C)

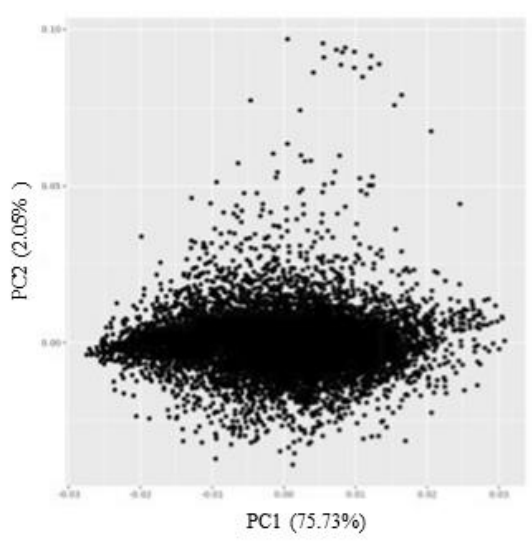

B)

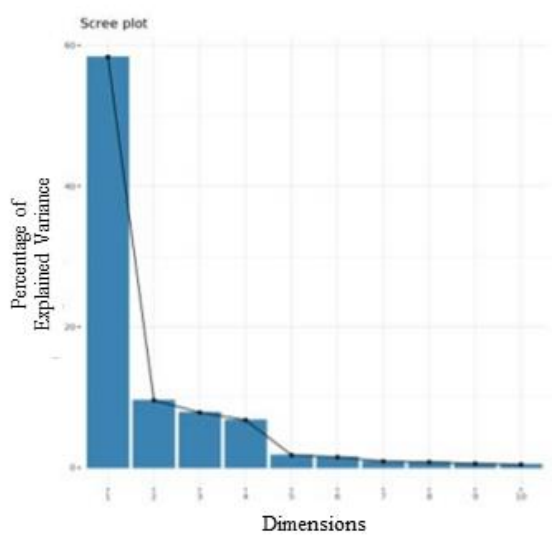

D)

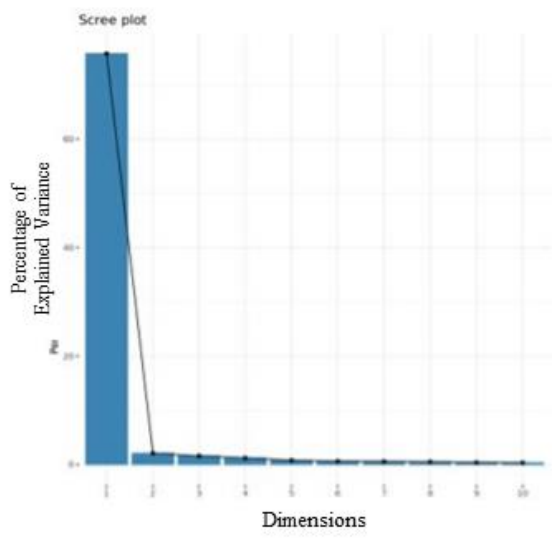


bioRxiv preprint doi: https://doi.org/10.1101/2019.12.16.870188; this version posted December 19, 2019. The copyright holder for this preprint (which was not certified by peer review) is the author/funder, who has granted bioRxiv a license to display the preprint in perpetuity. It is made available under aCC-BY-NC 4.0 International license.

Figure 2 Combined Microarray Data Score and Scree Plots (Components 1 \&2). A) Score plot before ComBat bath correction. B) Scree Plot Pre-ComBat batch correction. C) Score Plot of ComBat corrected Microarray Data. D) Scree Plot of ComBat corrected data.

A)

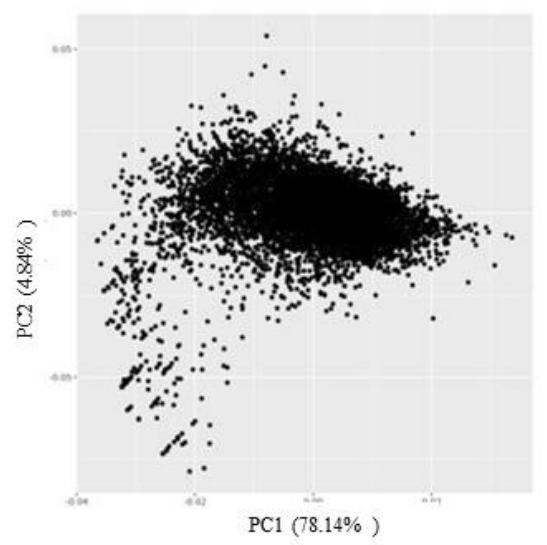

C)

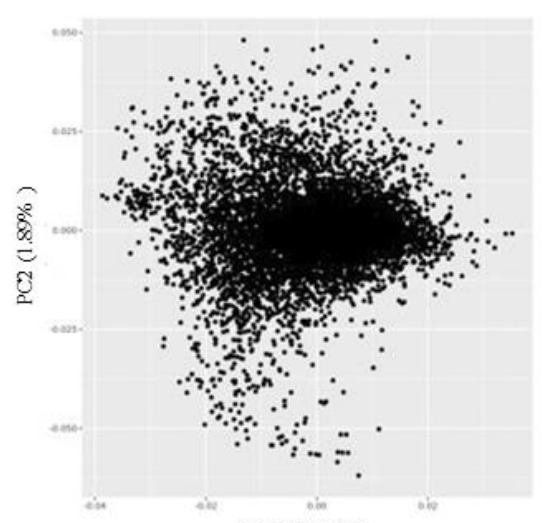

PC1 $(83.76 \%)$
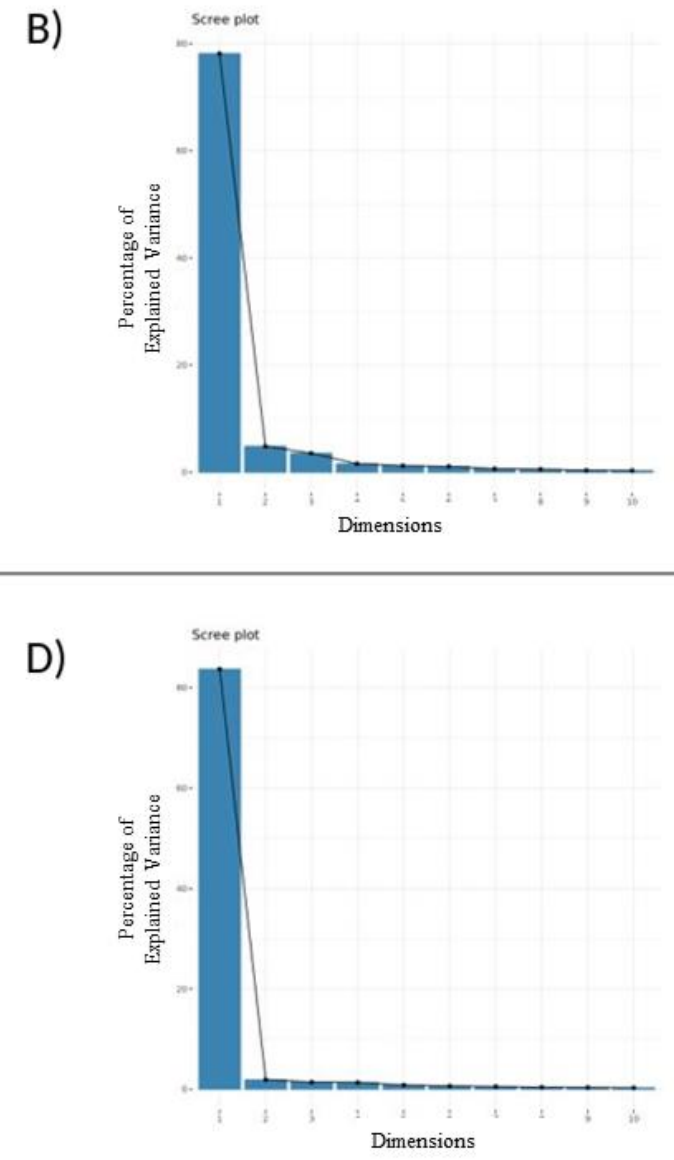
bioRxiv preprint doi: https://doi.org/10.1101/2019.12.16.870188; this version posted December 19, 2019. The copyright holder for this preprint (which was not certified by peer review) is the author/funder, who has granted bioRxiv a license to display the preprint in perpetuity. It is made available under aCC-BY-NC 4.0 International license.

Figure 3 Pearson's Correlation between batches and M3C distinguished clusters. $t=-1.1188, p=0.2635$, cor= .003535712. There is slight negative correlation, however not significant.

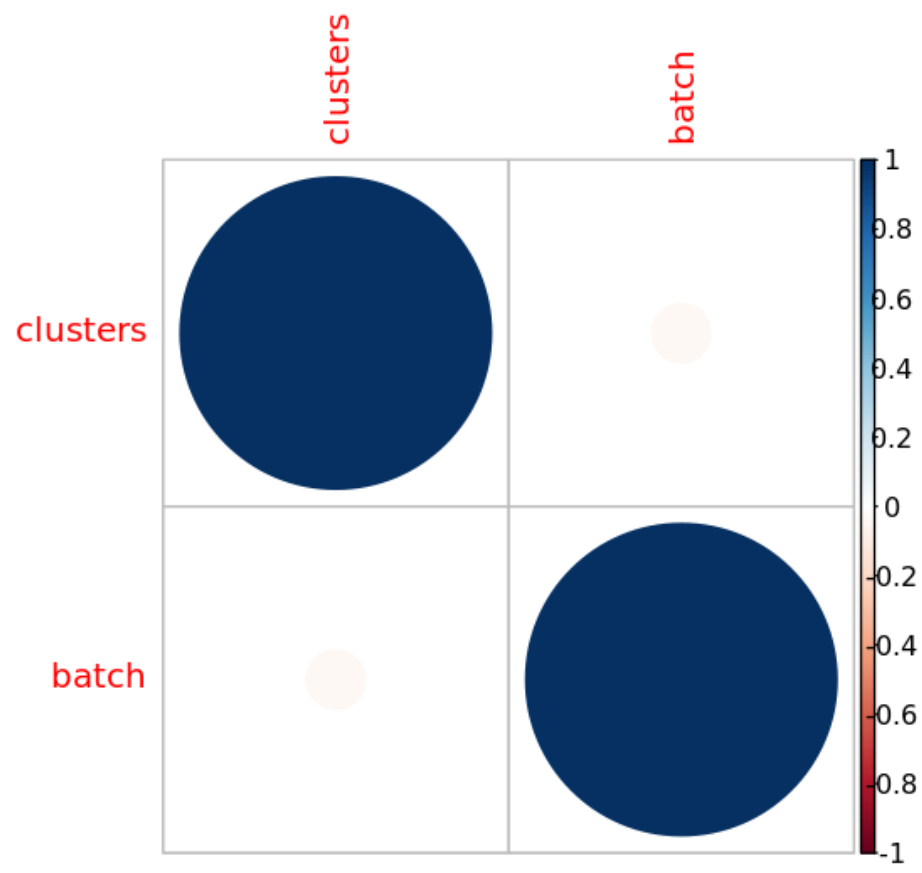


bioRxiv preprint doi: https://doi.org/10.1101/2019.12.16.870188; this version posted December 19, 2019. The copyright holder for this preprint

(which was not certified by peer review) is the author/funder, who has granted bioRxiv a license to display the preprint in perpetuity. It is made available under aCC-BY-NC 4.0 International license.

Table 1 Top 5 Significantly Differentiated Genes of Each Subtype.

\begin{tabular}{|c|c|c|c|c|c|c|c|}
\hline & & $\log F C$ & \begin{tabular}{|l}
$\begin{array}{l}\text { AveExpr } \\
(\log )\end{array}$ \\
\end{tabular} & $t$ & P.Value & adj.P.Val & B \\
\hline \multirow[b]{5}{*}{ CLASS 1} & AOX1 & -0.2697102765 & \begin{tabular}{|l}
7.383402014 \\
\end{tabular} & -24.71732052 & \begin{tabular}{|l|}
$1.05 \mathrm{E}-105$ \\
\end{tabular} & $6.97 \mathrm{E}-102$ & 230.3889938 \\
\hline & \begin{tabular}{|l|} 
FLRT2 \\
\end{tabular} & -0.2343510896 & 7.422330274 & -23.15971162 & \begin{tabular}{|l|}
$2.18 \mathrm{E}-95$ \\
\end{tabular} & $7.27 \mathrm{E}-92$ & 206.7464655 \\
\hline & \begin{tabular}{|l} 
SLC1A2 \\
\end{tabular} & -0.2736117953 & 7.197830691 & $\mid-22.22002319$ & \begin{tabular}{|l|}
$2.94 \mathrm{E}-89$ \\
\end{tabular} & $5.22 \mathrm{E}-86$ & 192.7045101 \\
\hline & \begin{tabular}{|l|} 
GAMT \\
\end{tabular} & -0.1698139592 & 7.439118734 & -22.21577758 & \begin{tabular}{|l|}
$3.13 \mathrm{E}-89$ \\
\end{tabular} & $5.22 \mathrm{E}-86$ & 192.6414979 \\
\hline & KCNJ5 & -0.2170978977 & 7.268332395 & -21.5335573 & \begin{tabular}{|l|}
$7.79 \mathrm{E}-85$ \\
\end{tabular} & $9.93 \mathrm{E}-82$ & 182.5707715 \\
\hline \multirow{6}{*}{ CLASS 2} & GAMT & 0.139585 & 7.439119 & 21.22054 & $7.79 \mathrm{E}-83$ & $5.20 \mathrm{E}-79$ & 177.955 \\
\hline & \begin{tabular}{|l|} 
P2RX1 \\
\end{tabular} & 0.200646 & 7.318828 & 20.76559 & $\begin{array}{l}6.02 \mathrm{E}-80 \\
\end{array}$ & $2.01 \mathrm{E}-76$ & 171.3457 \\
\hline & \begin{tabular}{|l|} 
NUCB2 \\
\end{tabular} & 0.134035 & 7.564929 & 19.83386 & \begin{tabular}{|l|}
$4.11 \mathrm{E}-74$ \\
\end{tabular} & $9.14 \mathrm{E}-71$ & 157.9919 \\
\hline & \begin{tabular}{|l|} 
RBPJL \\
\end{tabular} & 0.240064 & 7.297063 & 19.44479 & \begin{tabular}{|l|}
$1.04 \mathrm{E}-71$ \\
\end{tabular} & $1.73 \mathrm{E}-68$ & 152.4936 \\
\hline & \begin{tabular}{|l|} 
S100A6 \\
\end{tabular} & -0.11722 & 7.674083 & \begin{tabular}{|l|l|}
-19.4097 \\
\end{tabular} & \begin{tabular}{|l|}
$1.71 \mathrm{E}-71$ \\
\end{tabular} & $2.28 \mathrm{E}-68$ & 152.0004 \\
\hline & & $\log \mathrm{FC}^{* *}(-)$ & & & & & \\
\hline \multirow[b]{5}{*}{ CLASS 3} & \begin{tabular}{|l|} 
GAMT \\
\end{tabular} & -0.13959 & 7.439119 & -21.2205 & \begin{tabular}{|l|}
$7.79 \mathrm{E}-83$ \\
\end{tabular} & $5.20 \mathrm{E}-79$ & 177.955 \\
\hline & \begin{tabular}{|l|} 
P2RX1 \\
\end{tabular} & -0.20065 & 7.318828 & -20.7656 & \begin{tabular}{|l|}
$6.02 \mathrm{E}-80$ \\
\end{tabular} & $2.01 \mathrm{E}-76$ & 171.3457 \\
\hline & \begin{tabular}{|l|} 
NUCB2 \\
\end{tabular} & -0.13403 & 7.564929 & \begin{tabular}{|l|}
-19.8339 \\
\end{tabular} & \begin{tabular}{|l|}
$4.11 \mathrm{E}-74$ \\
\end{tabular} & $9.14 \mathrm{E}-71$ & 157.9919 \\
\hline & \begin{tabular}{|l|} 
RBPJL \\
\end{tabular} & -0.24006 & 7.297063 & \begin{tabular}{|l|}
-19.4448 \\
\end{tabular} & $1.04 \mathrm{E}-71$ & $1.73 \mathrm{E}-68$ & 152.4936 \\
\hline & \begin{tabular}{|l|} 
S100A6 \\
\end{tabular} & 0.117216 & 7.674083 & 19.40973 & \begin{tabular}{|l|}
$1.71 \mathrm{E}-71$ \\
\end{tabular} & $2.28 \mathrm{E}-68$ & 152.0004 \\
\hline \multirow[b]{5}{*}{ CLASS 4} & EPB41L4B & \begin{tabular}{|l|}
-0.19721 \\
\end{tabular} & 7.449825 & -19.9049 & $1.49 \mathrm{E}-74$ & $9.93 \mathrm{E}-71$ & 158.9589 \\
\hline & \begin{tabular}{|l|} 
RAB31 \\
\end{tabular} & 0.120711 & 7.595502 & 19.19366 & \begin{tabular}{|l|}
$3.60 \mathrm{E}-70$ \\
\end{tabular} & $1.20 \mathrm{E}-66$ & 148.9385 \\
\hline & \begin{tabular}{|l|} 
CDH11 \\
\end{tabular} & \begin{tabular}{|l|}
0.14974 \\
\end{tabular} & 7.544486 & 18.75932 & \begin{tabular}{|l|}
$1.57 \mathrm{E}-67$ \\
\end{tabular} & $3.50 \mathrm{E}-64$ & 142.9014 \\
\hline & \begin{tabular}{|l|} 
NUCB2 \\
\end{tabular} & -0.13217 & 7.564929 & -17.9862 & $6.68 \mathrm{E}-63$ & $1.11 \mathrm{E}-59$ & 132.3218 \\
\hline & RBPJL & $\mid-0.23903$ & 7.297063 & \begin{tabular}{|l|}
-17.8049 \\
\end{tabular} & \begin{tabular}{|l|}
$7.87 \mathrm{E}-62$ \\
\end{tabular} & $1.05 \mathrm{E}-58$ & 129.8736 \\
\hline \multirow[b]{5}{*}{ CLASS 5} & CPA2 & \begin{tabular}{|l|}
-0.38955 \\
\end{tabular} & \begin{tabular}{|l|}
7.48819 \\
\end{tabular} & -22.2839 & $1.13 \mathrm{E}-89$ & $7.55 \mathrm{E}-86$ & \begin{tabular}{|l|l|}
193.6168 \\
\end{tabular} \\
\hline & \begin{tabular}{|l|} 
PLA2G1B \\
\end{tabular} & -0.3834 & \begin{tabular}{|l|}
7.50473 \\
\end{tabular} & \begin{tabular}{|l|}
-22.0594 \\
\end{tabular} & $3.22 \mathrm{E}-88$ & $1.07 \mathrm{E}-84$ & 190.2892 \\
\hline & \begin{tabular}{|l|} 
CTRB2 \\
\end{tabular} & -0.30308 & 7.595823 & \begin{tabular}{|l|}
-22.007 \\
\end{tabular} & \begin{tabular}{|l|}
$7.01 \mathrm{E}-88$ \\
\end{tabular} & $1.56 \mathrm{E}-84$ & 189.5151 \\
\hline & CEL & $\mid-0.38869$ & 7.446912 & \begin{tabular}{|l|}
-21.8277 \\
\end{tabular} & \begin{tabular}{|l|}
$1.00 \mathrm{E}-86$ \\
\end{tabular} & $1.68 \mathrm{E}-83$ & 186.8672 \\
\hline & \begin{tabular}{|l|} 
CUZD1 \\
\end{tabular} & \begin{tabular}{|l|l|}
-0.34999 \\
\end{tabular} & 7.43262 & \begin{tabular}{|l|}
-21.3858 \\
\end{tabular} & $\begin{array}{l}6.87 \mathrm{E}-84 \\
\end{array}$ & $9.16 \mathrm{E}-81$ & 180.3775 \\
\hline \multirow[b]{5}{*}{ CLASS 6} & AP1M2 & -0.1625 & 7.441295 & -20.5203 & $2.12 \mathrm{E}-78$ & $1.41 \mathrm{E}-74$ & 167.7724 \\
\hline & EPCAM & -0.15343 & 7.670752 & $\mid-20.1773$ & \begin{tabular}{|l|}
$2.99 \mathrm{E}-76$ \\
\end{tabular} & $9.99 \mathrm{E}-73$ & 162.8536 \\
\hline & \begin{tabular}{|l|} 
ATP1B1 \\
\end{tabular} & -0.1353 & 7.716065 & -19.1836 & $4.15 \mathrm{E}-70$ & $9.21 \mathrm{E}-67$ & 148.8091 \\
\hline & \begin{tabular}{|l|} 
PLS1 \\
\end{tabular} & -0.20998 & 7.52294 & -19.0886 & \begin{tabular}{|l|}
$1.58 \mathrm{E}-69$ \\
\end{tabular} & $2.63 \mathrm{E}-66$ & 147.4828 \\
\hline & \begin{tabular}{|l|} 
CDS1 \\
\end{tabular} & $\mid-0.19613$ & 7.441095 & -18.9602 & \begin{tabular}{|l|}
$9.53 \mathrm{E}-69$ \\
\end{tabular} & $1.27 \mathrm{E}-65$ & 145.6956 \\
\hline
\end{tabular}


bioRxiv preprint doi: https://doi.org/10.1101/2019.12 16.870188; this version posted December 19, 2019. The copyright holder for this preprint (which was not certified by peer review) is the author/funder, who has granted bioRxiv a license to display the preprint in perpetuity. It is made available under aCC-BY-NC 4.0 International license.

Table 2 Performance of the Top Classification Model. A total error of 0.186047, at a rate of 56/301.

\begin{tabular}{|c|c|c|c|c|c|c|c|c|}
\hline & Class1 & Class2 & Class 3 & Class 4 & Class5 & Class6 & Error & Rate \\
\hline Class1 & 36 & 0 & 3 & 0 & 8 & 1 & 0.25 & $12 / 48$ \\
\hline Class2 & 0 & 20 & 5 & 1 & 0 & 0 & 0.230769 & $6 / 26$ \\
\hline Class 3 & 2 & 3 & 87 & 7 & 4 & 0 & 0.15534 & $16 / 103$ \\
\hline Class4 & 0 & 0 & 7 & 45 & 2 & 4 & 0.224138 & $13 / 58$ \\
\hline Class5 & 1 & 0 & 2 & 1 & 39 & 0 & 0.093023 & $4 / 43$ \\
\hline Class6 & 0 & 0 & 0 & 4 & 1 & 18 & 0.217391 & $5 / 23$ \\
\hline Totals & 39 & 23 & 104 & 58 & 54 & 23 & 0.186047 & $56 / 301$ \\
\hline
\end{tabular}


bioRxiv preprint doi: https://doi.org/10.1101/2019.12.16.870188; this version posted December 19, 2019. The copyright holder for this preprint (which was not certified by peer review) is the author/funder, who has granted bioRxiv a license to display the preprint in perpetuity. It is made available under aCC-BY-NC 4.0 International license.

Table 3 Proportion of batches in each subtype

\begin{tabular}{|c|c|c|c|c|c|c|}
\hline & $\begin{array}{l}\text { Proportion of } \\
\text { Batches in } \\
\text { Class } 1(\%)\end{array}$ & $\begin{array}{l}\text { Proportion of } \\
\text { Batches in } \\
\text { Class } 2(\%)\end{array}$ & $\begin{array}{l}\text { Proportion of } \\
\text { Batches in } \\
\text { Class } 3(\%)\end{array}$ & $\begin{array}{l}\text { Proportion of } \\
\text { Batches in } \\
\text { Class } 4(\%)\end{array}$ & $\begin{array}{l}\text { Proportion of } \\
\text { Batches in } \\
\text { Class } 5(\%)\end{array}$ & $\begin{array}{l}\text { Proportion of } \\
\text { Batches in } \\
\text { Class } 6(\%)\end{array}$ \\
\hline Batch 1 & 0 & 1 & 5 & 4 & 2 & 0 \\
\hline Batch 2 & 2 & 0 & 9 & 9 & 0 & 0 \\
\hline Batch 3 & 2 & 6 & 3 & 2 & 3 & 12 \\
\hline Batch 4 & 5 & 9 & 4 & 5 & 5 & 5 \\
\hline Batch 5 & 12 & 13 & 12 & 12 & 13 & 8 \\
\hline Batch 6 & 4 & 11 & 6 & 2 & 12 & 12 \\
\hline Batch 7 & 20 & 16 & 12 & 12 & 15 & 17 \\
\hline Batch 8 & 5 & 9 & 9 & 7 & 10 & 5 \\
\hline Batch 9 & 6 & 5 & 5 & 8 & 5 & 3 \\
\hline $\begin{array}{l}\text { Batch } \\
10\end{array}$ & 5 & 5 & 4 & 2 & 7 & 7 \\
\hline $\begin{array}{l}\text { Batch } \\
11\end{array}$ & 5 & 4 & 2 & 5 & 5 & 1 \\
\hline $\begin{array}{l}\text { Batch } \\
12\end{array}$ & 7 & 6 & 9 & 3 & 7 & 8 \\
\hline $\begin{array}{l}\text { Batch } \\
13\end{array}$ & 21 & 16 & 16 & 19 & 16 & 17 \\
\hline $\begin{array}{l}\text { Batch } \\
14\end{array}$ & 8 & 2 & 5 & 10 & 1 & 4 \\
\hline
\end{tabular}


bioRxiv preprint doi: https://doi.org/10.1101/2019.12.16.870188; this version posted December 19, 2019. The copyright holder for this preprint (which was not certified by peer review) is the author/funder, who has granted bioRxiv a license to display the preprint in perpetuity. It is made available under aCC-BY-NC 4.0 International license.

Figure 4: M3C algorithm applied to the cohort form Bailey et al. [1]. A) PAC scores display a sharp upwards spike at K=3, and a slight arch at K=4. B) CDF plot shows flattening of the consensus index curve as K increases. C) RSCI shows a sharp downwards spike at K=4. D)Plot of the P-value distribution over a logical distribution of $K$ values. Here, none of the ranks are significant.

A)

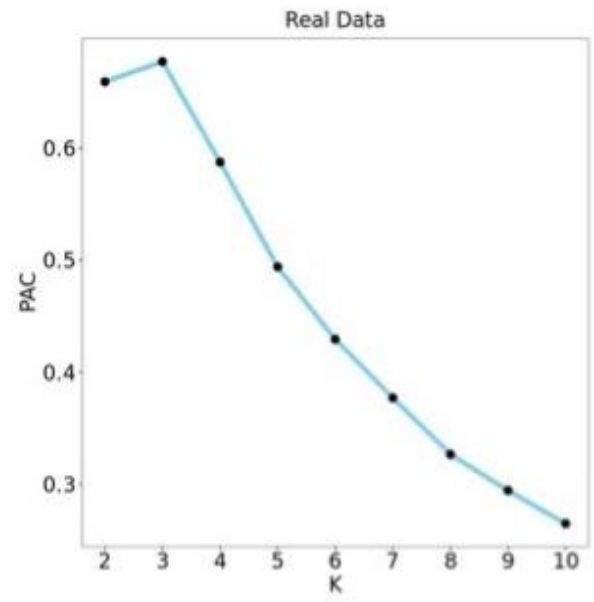

C)

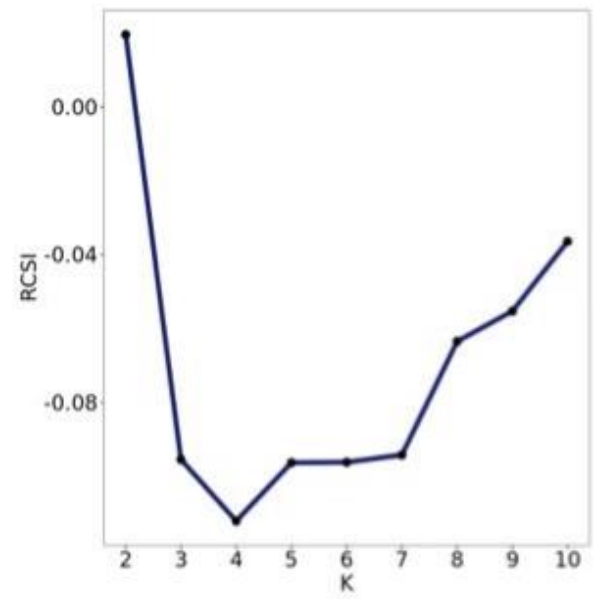

B)

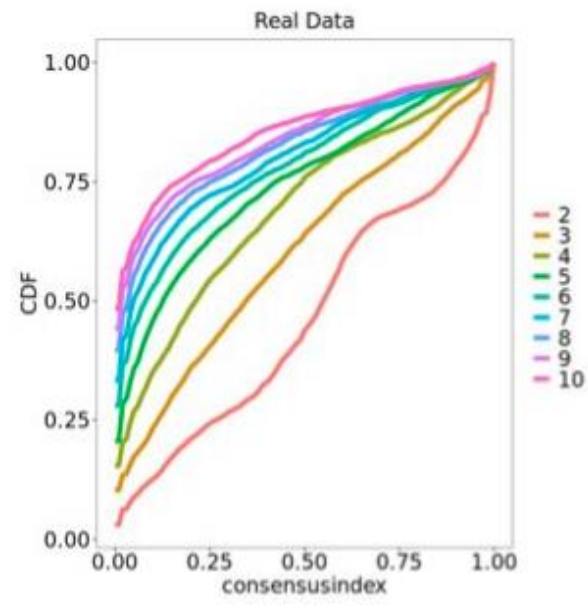

D)

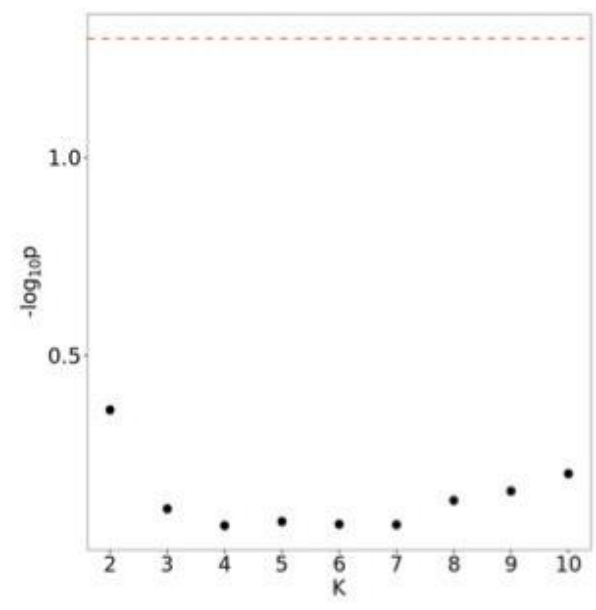


bioRxiv preprint doi: https://doi.org/10.1101/2019.12.16.870188; this version posted December 19,2019 . The copyright holder for this preprint (which was not certified by peer review) is the author/funder, who has granted bioRxiv a license to display the preprint in perpetuity. It is made available under aCC-BY-NC 4.0 International license.

A)

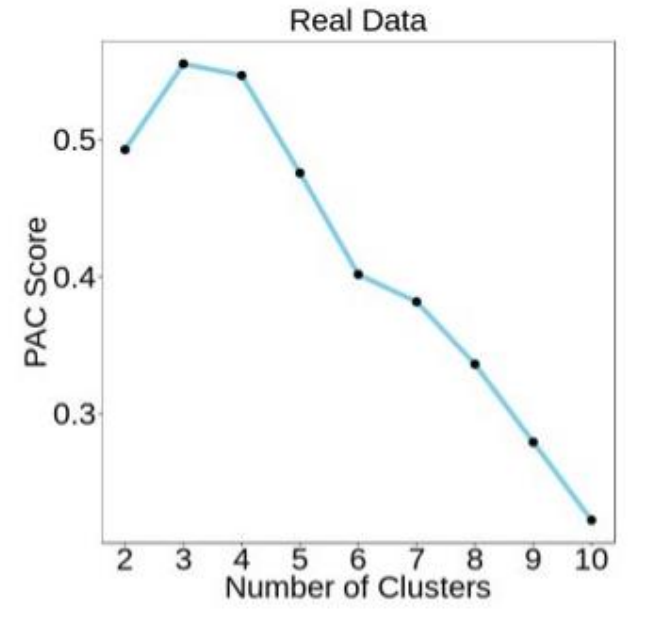

C)

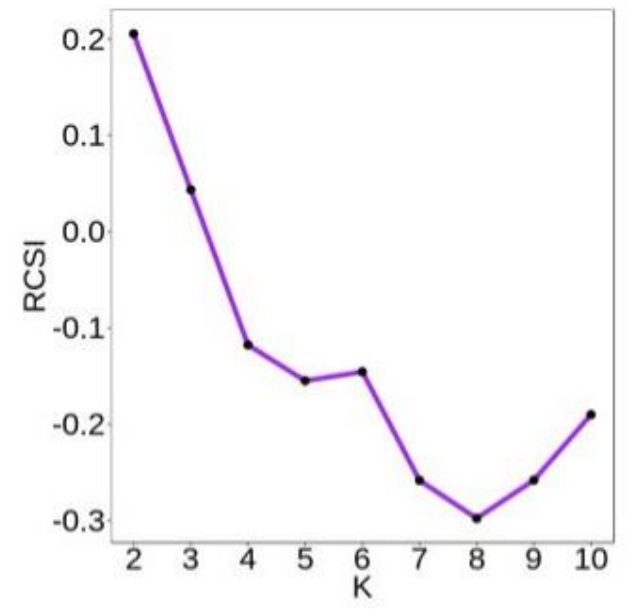

B)

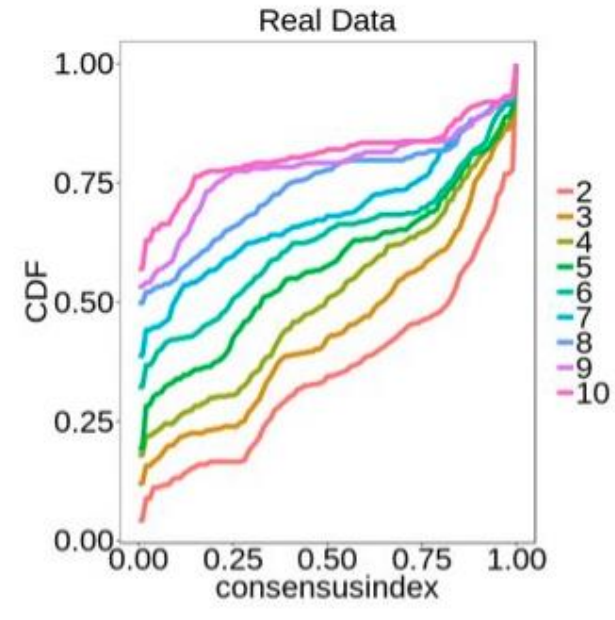

D)

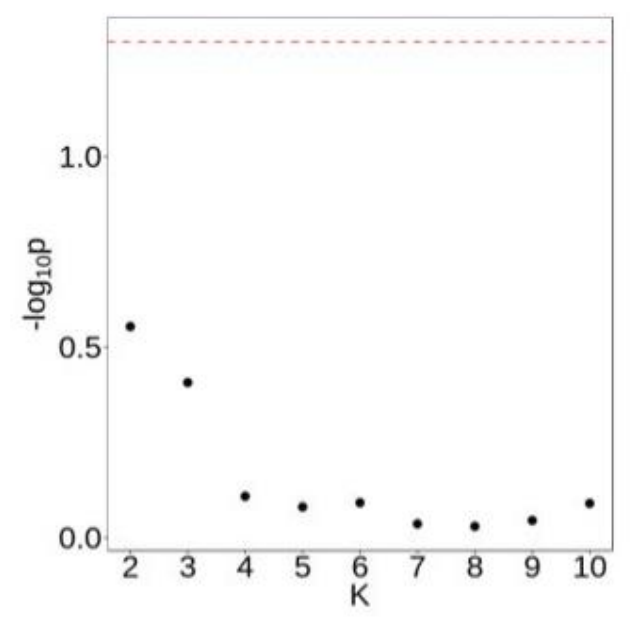

